\title{
Baseline Blood-Brain Barrier Leakage and Longitudinal Microstructural Tissue Damage in the Periphery of White Matter Hyperintensities
}

Danielle Kerkhofs, MD,* Sau May Wong, PhD, * Eleana Zhang, PhD, MD, Julie Staals, PhD, MD, Jacobus F.A. Jansen, PhD, Robert J. van Oostenbrugge, PhD, MD, and Walter H. Backes, PhD

Neurology ${ }^{\circledR}$ 2021;96:e2192-e2200. doi:10.1212/WNL.0000000000011783

\section{Abstract}

\section{Objective}

To investigate the 2-year change in parenchymal diffusivity, a quantitative marker of microstructural tissue condition, and the relationship with baseline blood-brain barrier (BBB) permeability, in tissue at risk, i.e., the perilesional zone surrounding white matter hyperintensities $(\mathrm{WMH})$ in patients with cerebral small vessel disease (cSVD).

\section{Methods}

Patients with sporadic cSVD (lacunar stroke or mild vascular cognitive impairment) underwent 3T MRI at baseline, including dynamic contrast-enhanced MRI to quantify BBB permeability (i.e., leakage volume and rate) and intravoxel incoherent motion imaging (IVIM), a diffusion technique that provides parenchymal diffusivity $D$. After 2 years, IVIM was repeated. We assessed the relation between BBB leakage measures at baseline and change in parenchymal diffusivity $(\Delta D)$ over 2 years in the perilesional zones (divided in 2-mm contours) surrounding WMH.

\section{Results}

We analyzed 43 patients (age $68 \pm 12$ years, $58 \%$ male). In the perilesional zones, $\Delta D$ increased $0.10 \%$ (confidence interval [CI] $0.07-0.013 \%)(p<0.01)$ per $2 \mathrm{~mm}$ closer to the WMH. Furthermore, $\Delta D$ over 2 years showed a positive correlation with both baseline BBB leakage volume $(r=0.29$ [CI 0.06-0.52], $p=0.013)$ and leakage rate $(r=0.24$ [CI 0.02-0.47], $p=$ $0.034)$.

\section{Conclusion}

$\mathrm{BBB}$ leakage at baseline is related to the 2-year change in parenchymal diffusivity in the perilesional zone of WMH. These results support the hypothesis that BBB impairment might play an early role in subsequent microstructural white matter degeneration as part of the pathophysiology of cSVD.

\author{
Correspondence \\ Dr. Kerkhofs \\ danielle.kerkhofs@mumc.nl
}




\section{Glossary}

$\Delta D=$ relative change in diffusivity; $\mathbf{B B B}=$ blood-brain barrier; $\mathbf{C G M}=$ cortical gray matter $\mathbf{C I}=$ confidence interval; $\mathbf{c S V D}=$ cerebral small vessel disease; DCE = dynamic contrast-enhanced; DST = dynamic scan time; DW = diffusion-weighted; FLAIR = fluid-attenuated inversion recovery; FOV = field of view; IVIM = intravoxel incoherent motion; $K_{\mathbf{i}}=$ leakage rate; $\mathbf{m V C I}=$ mild vascular cognitive impairment; $\mathbf{N A W M}=$ normal-appearing white matter; $\mathbf{N V U}=$ neurovascular unit; $\mathbf{T D}=$ time delay; $\mathbf{T E}=$ echo time; $\mathbf{T I}=$ inversion time; $\mathbf{T R}=$ repetition time; $\mathbf{v}_{\mathbf{L}}=$ leakage volume; $\mathbf{W M H}=$ white matter hyperintensities.

Cerebral small vessel disease (cSVD) is a common age- and vascular risk factor-related disease and may cause lacunar stroke and cognitive impairment. ${ }^{1}$ White matter hyperintensities $(\mathrm{WMH})$, a radiologic marker frequently found in cSVD, are assumed to be a manifestation of vascular damage to the white matter and can be considered as a surrogate marker of disease severity. ${ }^{2-5}$

Blood-brain barrier (BBB) disruption is thought to be at the basis of microstructural alterations that eventually lead to brain tissue degeneration visible as WMH on MRI. Using dynamic contrast-enhanced (DCE) MRI, it was previously shown that BBB permeability is increased in CSVD and correlates to disease burden in terms of WMH load. ${ }^{6-10}$ However, $\mathrm{WMH}$ represent macrostructural consequences of microvascular pathology, while the tissue microstructure is likely impaired before and beyond such visible lesions. To determine the condition of the parenchymal microstructure, we propose intravoxel incoherent motion (IVIM) imaging, which is a diffusion-weighted MRI technique that can quantitatively measure parenchymal diffusivity without the influence or contribution of water diffusion in the blood vessels. ${ }^{11}$ It was demonstrated earlier that patients with CSVD have an increased diffusivity of the normal-appearing white matter (NAWM) compared to controls. ${ }^{12,13}$

Longitudinal data on the influence of BBB permeability on microstructural alternations are needed to determine the sequence of the pathophysiologic events to proclaim on a potential causal relation. In patients with cSVD, we investigated the relation between BBB permeability at baseline and the longitudinal change in parenchymal diffusivity over 2 years in the perilesional zone around $\mathrm{WMH}$.

\section{Methods}

Inclusion and imaging methods of this study have been described previously. ${ }^{7,12,14}$

\section{Study Population}

In this longitudinal study, we included patients with clinically manifest cSVD, consisting of lacunar stroke or mild vascular cognitive impairment (mVCI). Inclusion criterion for lacunar stroke was a first-ever acute stroke syndrome with a compatible recent small subcortical infarct on brain MRI. If no such lesion was visible on MRI, established clinical criteria for lacunar stroke syndrome were used. ${ }^{15,16}$ Exclusion criteria included a symptomatic carotid stenosis of $\geq 50 \%$ or a possible cardiac embolic source (e.g., atrial fibrillation). To avoid measuring acute effects, patients with stroke were included at least 3 months poststroke. Criteria for mVCI consisted of subjective cognitive dysfunction, objective cognitive impairment determined by neuropsychological assessment in at least one cognitive domain, and widespread WMH on brain MRI that suggested a link between cognitive deficit and cSVD: moderate to severe WMH (Fazekas score deep $>1$ or periventricular $>2$ ) or mild WMH (Fazekas score deep $=1$ or periventricular $=2$ ) combined with lacunes or microbleeds. ${ }^{17,18}$ Furthermore, patients were excluded if a neurodegenerative disease other than vascular cognitive impairment was suspected (e.g., Alzheimer disease), or in case of severe cognitive impairment, defined as a Clinical Dementia Rating score of $>1$ or a Mini-Mental State Examination score of $<20$. Other exclusion criteria were a history of cerebrovascular disease or diagnoses of other CNS diseases or contraindications for MRI. Characteristics that were recorded at baseline included age, sex, and cardiovascular factors such as hypertension (history of hypertension/antihypertensive medication), hypercholesterolemia (history of hypercholesterolemia/statin), diabetes (history of diabetes/diabetes medication), current smoking, and body mass index. ${ }^{7}$

Patients were recruited from the Maastricht University Medical Centre and Zuyderland Medical Centre, the Netherlands, between April 2013 and February 2015. Follow-up measurements were performed after 2 years in the period between June 2015 and March 2017.

\section{Standard Protocol Approvals, Registrations, and Patient Consents}

The study was approved by the Medical Ethics Committee of the Maastricht University Medical Center. Written informed consent was obtained from all participants (or guardians of participants) in the study (consent for research).

\section{Imaging}

All patients underwent brain imaging on a 3T MRI system (Achieva TX, Philips Healthcare, Best, the Netherlands) at baseline and 2-year follow-up using a 32-element head coil suitable for parallel imaging. Structural MRI included a T1weighted sequence (repetition time $[\mathrm{TR}] /$ inversion time [TI]/echo time [TE] 8.3/800/3.8 ms; field of view [FOV] $256 \times 256 \times 160 \mathrm{~mm} ; 1.0 \mathrm{~mm}$ cubic voxel size) and a T2weighted fluid-attenuated inversion recovery (FLAIR) sequence (TR/TI/TE 4,800/1,650/299 ms; FOV $256 \times 256 \times$ 
$180 \mathrm{~mm}$; $1.0 \mathrm{~mm}$ cubic voxel size) for anatomic reference and detection of $\mathrm{WMH} .^{7,9}$

\section{DCE-MRI}

At baseline, dual-time resolution DCE-MRI was performed by 2 integrated dynamic saturation recovery gradient recalled sequences (flip angle $10^{\circ}, 90^{\circ}$ nonselective saturation prepulse, time delay [TD] of $120 \mathrm{~ms}$ ) with different dynamic scan time (DST), the fast and the slow sequence. ${ }^{7,9,19}$ First, precontrast scans of both the fast and slow sequences were obtained before bolus injection. Then, the contrast agent was injected (gadobutrol; dose $0.1 \mathrm{mmol} / \mathrm{kg}$ body weight) in the antecubital vein at a rate of $3 \mathrm{~mL} / \mathrm{s}$ followed by a $20 \mathrm{~mL}$ saline flush using a power injector. During the injection, the fast sequence was applied (DST 3.2 seconds, TR/TE/TD 5.6/2.5/120 ms, flip angle $30^{\circ}$, FOV $256 \times 200 \times 50 \mathrm{~mm}$, voxel size $2 \times 2 \times 5 \mathrm{~mm}$, image acquisition acceleration [SENSE] factor 2, 29 image volumes including 9 precontrast volumes, duration 1:33 min:s). Subsequently the slow sequence (DST 30.5 seconds, TR/TE/TD $5.6 / 2.5 / 120$, flip angle $30^{\circ}$, FOV $256 \times 256 \times 100 \mathrm{~mm}$, voxel size of $1 \times 1 \times 2 \mathrm{~mm}$, SENSE factor 2, 45 image volumes including 3 precontrast volumes, duration 22:53 min:s) was performed. The fast and slow sequences overlapped spatially with the periventricular region, the most vulnerable region in patients with cSVD. $^{20}$ T1 mapping with variable delay time (TD 120-4,000 $\mathrm{ms}$ ) was performed before contrast agent administration and DCE-MRI to convert the contrast-enhanced signal intensities to concentrations in tissue. $^{21}$

\section{IVIM Imaging}

At baseline and 2-year follow-up, IVIM imaging was conducted as described before. ${ }^{12,22}$ We employed a Stejskal-Tanner diffusion-weighted (DW) single shot spin-echo echoplanar imaging pulse sequence (TR/TE 6,800/84 ms; FOV $221 \times 269$ $\times 139 \mathrm{~mm}^{3} ; 2.4 \mathrm{~mm}^{3}$ cubic voxel size; duration 5:13 min:s). To minimize the signal contribution of CSF, an inversion recovery pulse (TI 2,230 ms) was applied prior to the DW sequence. ${ }^{23}$ Fifteen volume images were acquired with the diffusion sensitization gradient encoding in the anterior-posterior direction using multiple $b$ values $(0,5,7,10,15,20,30,40,50,60,100$, $200,400,700$, and $\left.1,000 \mathrm{~s} / \mathrm{mm}^{2}\right)$. To increase the signal-to-noise ratio at high $b$ values, the number of signal means for the highest $2 b$ values were 2 and 3 , instead of 1 , respectively. ${ }^{12}$

\section{Image Processing and Analyses}

\section{DCE-MRI}

\section{Pharmacokinetic Modeling}

Analysis of the DCE-MRI data consists of pharmacokinetic modeling and histogram analysis as described before. ${ }^{7,19}$ For this purpose, the graphical Patlak method was employed to relate concentration time course of brain tissue and blood. ${ }^{24}$ For this method, the contrast agent concentration in tissue was calculated by using the relative signal enhancement, $\mathrm{T} 1$ mapping, and the concentration in blood plasma in the superior sagittal sinus as the vascular input function. ${ }^{21}$ Using the slope in the Patlak plot, the transfer constant $K_{\mathrm{i}}\left(\mathrm{min}^{-1}\right)$ was calculated as a measure of leakage rate.

\section{Histogram Analysis}

$K_{\mathrm{i}}$ was determined in a voxel-wise manner and a histogram was composed of the $K_{\mathrm{i}}$ values in each tissue region, as described earlier. ${ }^{14}$ Noise correction was achieved by mirroring the negative $K_{\mathrm{i}}$ values to the positive axis and subtracting both parts from the original $K_{\mathrm{i}}$ distribution, resulting in a histogram of (the remaining positive) $K_{\mathrm{i}}$ values, which reflect the detectable leakage rates. Quantitative measures of $\mathrm{BBB}$ leakage per tissue region were obtained from this histogram: the mean $K_{\mathrm{i}}$ was calculated as the mean of all the positive noise-corrected voxels and the leakage volume $\left(v_{L}\right)$, which was the total residual area under the (positive) histogram curve, representing the spatial extent of the leakage. ${ }^{7}$

\section{Image Processing and Analyses}

\section{IVIM Imaging}

Preprocessing of the IVIM images has been described previously and consisted of spatial distortion corrections (echoplanar imaging and eddy current distortions) and head displacements (ExploreDTI v4.8.3 and v4.8.6). ${ }^{12,22,25}$ Subsequently, baseline and follow-up IVIM images were coregistered to the corresponding baseline T1-weighted image and spatially smoothed with a $3 \mathrm{~mm}$ full-width-at-half-maximum Gaussian kernel. The IVIM signal decay was fitted with a biexponential curve by using a modified 2-compartment diffusion model representing a vascular and a nonvascular component, which also accounts for contamination of CSF and differences in relaxation time between tissue and blood. ${ }^{23}$ The vascular component is thought to embody the fast water motion in blood flowing into a random network of small vessels and the nonvascular component is determined by the water diffusion in the parenchymal microstructure represented by the parenchymal diffusivity $D$. Model fitting was performed on a voxel-by-voxel basis using a 2-step method separating the monoexponential decay at the high $b$ values from the biexponential decay at the lowest $\mathrm{b}$ value. ${ }^{26}$ This resulted in the parenchymal diffusivity $D$, which was corrected for fast water motion in blood and was calculated for the baseline and follow-up scans. The relative change in $D$ over time was calculated as follows: $\Delta D(\%)=100 \times$ $\left(D_{\text {Follow-up }}-D_{\text {Baseline }}\right) / D_{\text {Baseline }}$.

\section{Tissue Regions}

Gray and white matter were segmented (Freesurfer ${ }^{27}$ ) in the baseline T1-weighted images. WMH were automatically segmented, with manual correction by a trained investigator under supervision of 2 experienced vascular neurologists, on baseline FLAIR scans. ${ }^{28}$ All images were coregistered to the DCE-MRI space: baseline FLAIR and T1-weighted images, baseline and follow-up IVIM images were coregistered to the precontrast DCE-MRI scans (FSL, v5.0). ${ }^{29}$ The following brain regions were selected: cortical gray matter (CGM), 
Table 1 Characteristics of the Study Population

\begin{tabular}{ll}
\hline Age, y, mean \pm SD & $\mathbf{N}=\mathbf{4 3}$ \\
\hline Male & $68 \pm 12$ \\
\hline Lacunar stroke/mVCI & $25(58)$ \\
\hline Time to follow-up MRI, mo, mean \pm SD & $30(70) / 13(30)$ \\
\hline Hypertension & $25 \pm 1$ \\
\hline Diabetes & $27(63)$ \\
\hline Smoking & $4(9)$ \\
\hline Hypercholesterolemia & $13(30)$ \\
\hline BMI, kg/m ${ }^{2} \pm$ SD & $27(63)$ \\
\hline Total WMH Fazekas score, median (IQR) & $25 \pm 4$ \\
\hline Relative WMH volume (SE) & $4(2-6)$ \\
\hline
\end{tabular}

Abbreviations: $\mathrm{BMI}=$ body mass index; $\mathrm{IQR}=$ interquartile range; $\mathrm{mVCl}=$ mild vascular cognitive impairment; $\mathrm{SE}=$ standard error; $\mathrm{WMH}=$ white matter hyperintensities.

Values are $\mathrm{n}(\%)$ unless otherwise indicated. Total Fazekas score: periventricular (0-3) and deep (0-3) WMH scores were summed.

NAWM, and WMH. The volume of WMH was normalized to the intracranial volume to calculate relative $\mathrm{WMH}$ volume.

Next, the perilesional zone adjacent to WMH was selected: the NAWM was divided into a number of perilesional shells by segmenting 6 contours of 2-mm width using a dilation operation of $2 \mathrm{~mm}$ around the $\mathrm{WMH} .{ }^{14}$ For all tissue regions and the perilesional zones, baseline BBB measures, $K_{\mathrm{i}}$ and $\mathrm{v}_{\mathrm{L}}$, and IVIM measures, $D_{\text {Baseline, }} D_{\text {Follow-up, }}$ and $\Delta D(\%)$, were calculated.

\section{Statistical Analysis}

Leakage and diffusivity measures were compared among the different tissue regions (cortex, NAWM, and WMH) using a paired $t$ test. For each tissue region, univariable regression analysis was performed between the baseline BBB measures
$\left(K_{\mathrm{i}}\right.$ and $\left.\mathrm{v}_{\mathrm{L}}\right)$ as independent variable and the longitudinal change in parenchymal diffusivity $(\Delta D)$ as dependent variable.

For the perilesional zone, regression analysis was performed between mean baseline BBB measures and distance to WMH and between mean $\Delta D$ and distance to $\mathrm{WMH}$. Then, 2 analyses were performed to investigate the relation between the baseline $\mathrm{BBB}$ measures and $\triangle D$ within the perilesional zone: (1) per patient, the spatial relation between the leakage measures and longitudinal change in parenchymal diffusivity $\Delta D$ was assessed as a function of distance to the WMH using the Pearson correlation; (2) per contour of the perilesional zone, the mean leakage measures and mean longitudinal diffusivity change $\Delta D$ over all patients were calculated. The spatial relation between the mean leakage measures and mean longitudinal diffusivity change $\Delta D$ was studied using linear regression. All statistical analyses were performed using SPSS; $p<0.05$ was considered statistically significant.

\section{Data Availability}

The data that support the findings of this study are available from the corresponding author, upon reasonable request.

\section{Results}

\section{Patient Characteristics}

At baseline, 81 patients with cSVD were included. We obtained follow-up data for 51 of these patients, 4 patients died during the follow-up period, and 26 patients were not willing to participate in the follow-up study. Eight additional patients were excluded from data analysis due to imaging complication or artifacts at baseline or follow-up. The 43 patients suitable for analysis did not differ from the patients who only completed baseline measurements regarding sex (male $58.1 \%$ vs $57.9 \%$, respectively, $p=0.983$ ), but were younger ( $67.7 \pm 12.0$ years vs $72.6 \pm 9.8$ years, respectively, $p=0.048)$. The relative WMH volume at baseline was not different for the patients included in this study as compared to the patients with only baseline data $(0.013 \pm 0.013$ vs $0.017 \pm$

Table 2 Leakage and Diffusivity Measures for the Different Brain Regions

\begin{tabular}{|c|c|c|c|}
\hline \multirow[b]{2}{*}{ MRI measure } & \multicolumn{3}{|c|}{ Brain region, mean \pm SEM } \\
\hline & NAWM & WMH & CGM \\
\hline $\mathrm{v}_{\mathrm{L}}(\%)$ & $31.1 \pm 2.3$ & $37.2 \pm 2.7$ & $15.4 \pm 1.6$ \\
\hline$K_{\mathrm{i}}\left(\times 10^{-4} \min ^{-1}\right)$ & $3.05 \pm 0.25$ & $3.35 \pm 0.20$ & $2.07 \pm 0.28$ \\
\hline$D_{\text {Baseline }}\left(\times 10^{-4} \mathrm{~mm}^{2} / \mathrm{s}\right)$ & $7.37 \pm 0.05$ & $8.89 \pm 0.14$ & $7.30 \pm 0.03$ \\
\hline$D_{\text {Follow-up }}\left(\times 10^{-4} \mathrm{~mm}^{2} / \mathrm{s}\right)$ & $7.46 \pm 0.06$ & $9.01 \pm 0.16$ & $7.38 \pm 0.04$ \\
\hline$\Delta D(\%)$ & $1.20 \pm 0.30$ & $1.42 \pm 0.66$ & $1.02 \pm 0.30$ \\
\hline
\end{tabular}

Abbreviations: $\Delta D=$ relative change in diffusivity; $C G M=$ cortical gray matter; $D_{\text {Baseline }}=$ baseline diffusivity; $D_{\text {Follow-up }}=$ follow-up diffusivity; $K_{\mathrm{i}}=$ leakage rate; $\mathrm{NAWM}=$ normal-appearing white matter; $\mathrm{v}_{\mathrm{L}}=$ leakage volume; $\mathrm{WMH}=$ white matter hyperintensities. 
Table 3 Association Between Longitudinal Change in Diffusivity, Leakage Volume, and Leakage Rate

\begin{tabular}{|c|c|c|c|c|}
\hline \multirow[b]{2}{*}{$\Delta D$} & \multicolumn{2}{|l|}{$\mathbf{v}_{\mathrm{L}}$} & \multicolumn{2}{|l|}{$K_{\mathrm{i}}$} \\
\hline & $\beta$ & $p$ Value & $\beta$ & $p$ Value \\
\hline NAWM & -0.071 & 0.650 & 0.092 & 0.559 \\
\hline WMH & 0.237 & 0.130 & 0.123 & 0.438 \\
\hline CGM & -0.025 & 0.874 & 0.045 & 0.772 \\
\hline
\end{tabular}

Abbreviations: $\Delta D=$ relative change in diffusivity; $C G M=$ cortical gray matter; $K_{\mathrm{i}}=$ leakage rate; $N A W M=$ normal-appearing white matter; $v_{\mathrm{L}}=$ leakage volume; $\mathrm{WMH}=$ white matter hyperintensities.

0.016, respectively, $p=0.266)$. The mean time between baseline and follow-up MRI scan was $25 \pm 1$ months. The characteristics of included patients are shown in table 1 .

\section{Cortex, White Matter, and WMH}

First, we analyzed the CGM, NAWM, and WMH. The mean baseline values of leakage volume $\mathrm{v}_{\mathrm{L}}$ and leakage rate $K_{\mathrm{i}}$ for these brain regions are presented in table 2 . Both leakage volume $\mathrm{v}_{\mathrm{L}}$ and leakage rate $K_{\mathrm{i}}$ were higher in the $\mathrm{WMH}$ than in the NAWM (mean difference [95\% confidence interval $(\mathrm{CI})] \mathrm{v}_{\mathrm{L}}: 6.1[1.3-9.6] \%, p=0.001 ; K_{\mathrm{i}}: 0.30[0.04-0.55] \times$ $\left.10^{-4} \min ^{-1}, p=0.023\right)$ and higher in the NAWM than in the $\operatorname{CGM}\left(\mathrm{v}_{\mathrm{L}}: 15.7[12.6-18.8] \%, p<0.001 ; K_{\mathrm{i}}: 0.98[0.63-1.33]\right.$ $\left.\times 10^{-4} \mathrm{~min}^{-1}, p<0.001\right)$.

The mean values of baseline diffusivity $D_{\text {Baseline, follow-up }}$ diffusivity $D_{\text {Follow-up, }}$ and the longitudinal change in diffusivity $\Delta D$ for all tissue regions are also presented in table 2 . Both baseline diffusivity $D_{\text {Baseline }}$ and follow-up diffusivity $D_{\text {Follow-up }}$ were higher in the WMH than in the NAWM (mean difference $D_{\text {Baseline }}: 1.47[1.27-1.67] \times 10^{-4} \mathrm{~mm}^{2} / \mathrm{s}, p<0.001$; $\left.D_{\text {Follow-up }}: 1.51[1.28,1.75] \times 10^{-4} \mathrm{~mm}^{2} / \mathrm{s}, p<0.001\right)$ and higher in the NAWM than in the CGM ( $D_{\text {Baseline: }} 0.07$ [0.01-0.12] $\times 10^{-4} \mathrm{~mm}^{2} / \mathrm{s}, p=0.024 ; D_{\text {Follow-up }} 0.08$ $\left.[0.02-0.14] \times 10^{-4} \mathrm{~mm}^{2} / \mathrm{s}, p=0.009\right)$.

The longitudinal change in diffusivity $\Delta D$ was highest in WMH and lowest in CGM but these were not significantly different. There was no association between the baseline leakage measures $\mathrm{v}_{\mathrm{L}}$ and $K_{\mathrm{i}}$ and change in diffusivity $\Delta D$ over 2 years in any of these tissue regions (table 3 ).

\section{Perilesional Zones}

In figure 1, example maps of the perilesional zones, leakage rate $K_{\mathrm{i}}$, and parenchymal diffusivity $(D)$ are shown. In figure 2 , we present the mean values of leakage volume $\mathrm{v}_{\mathrm{L}}$, leakage rate $K_{\mathrm{i}}$, and longitudinal change in diffusivity $\Delta D$ over the $2 \mathrm{~mm}$ contours of the perilesional zones. Regression analysis of BBB

Figure 1 Fluid-Attenuated Inversion Recovery (FLAIR) Image, Perilesional Zones, and Leakage and Diffusivity Maps
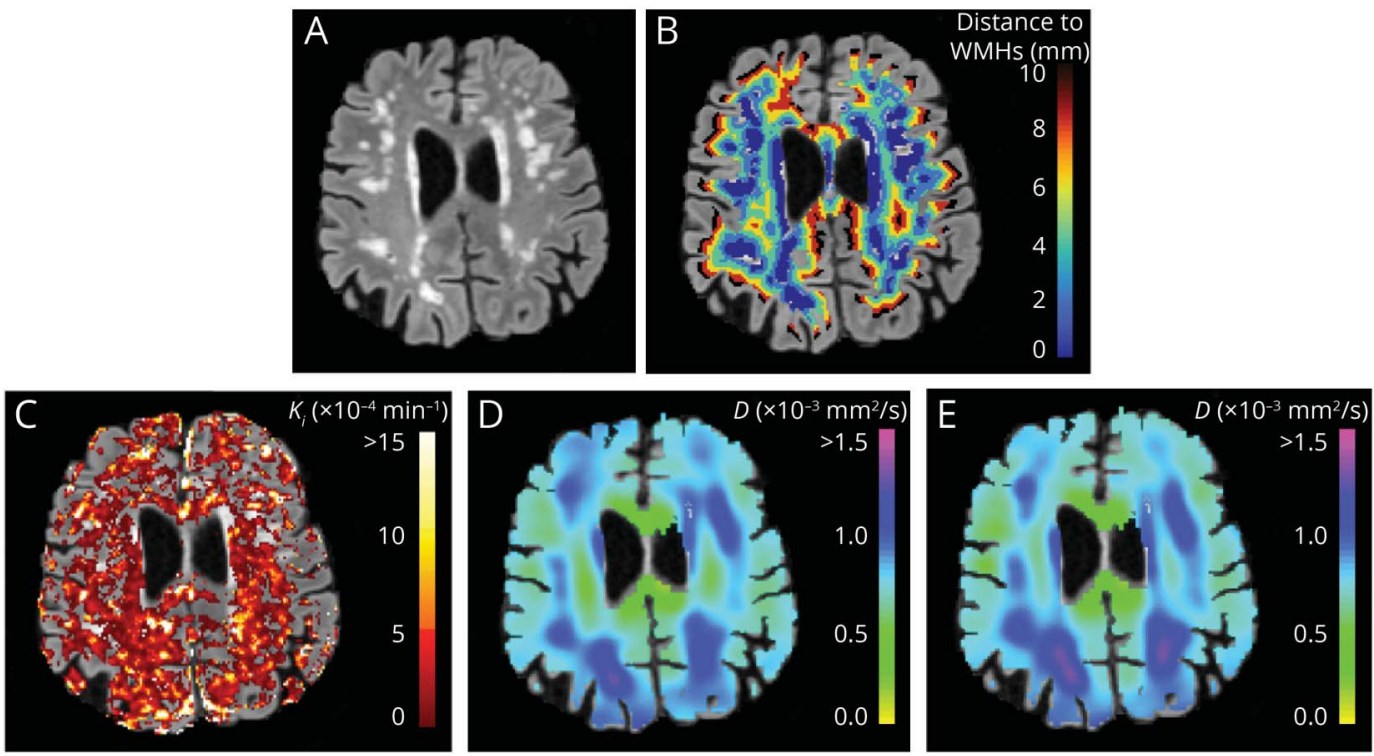

FLAIR image at baseline $(A)$, perilesional zones at baseline $(B)$, leakage rate $\left(K_{i}\right)$ map at baseline $(C)$, and the parenchymal diffusitivity maps at baseline $(D)$ and follow-up (E) from a patient with cerebral small vessel disease (Female, 52 years of age). WMH = white matter hyperintensities. 
Figure 2 Leakage Volume, Leakage Rate, and Longitudinal Change in Parenchymal Diffusivity for the Perilesional Zones

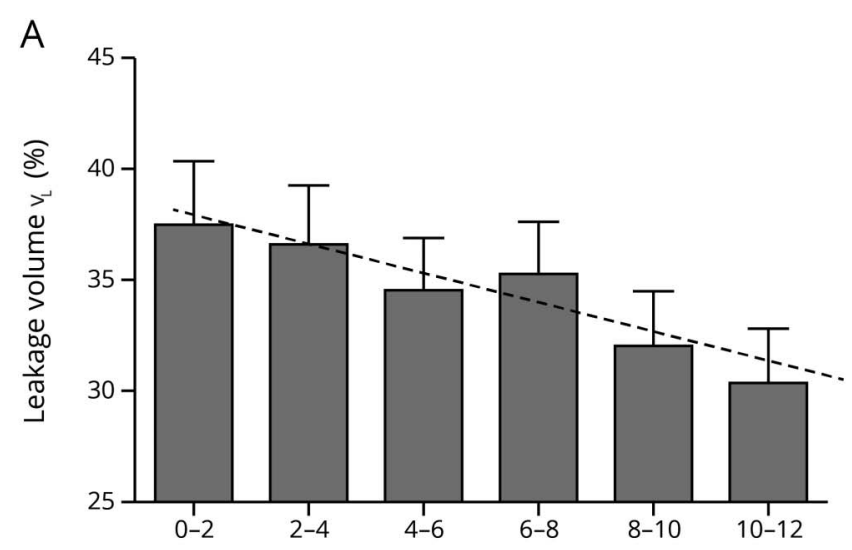

B

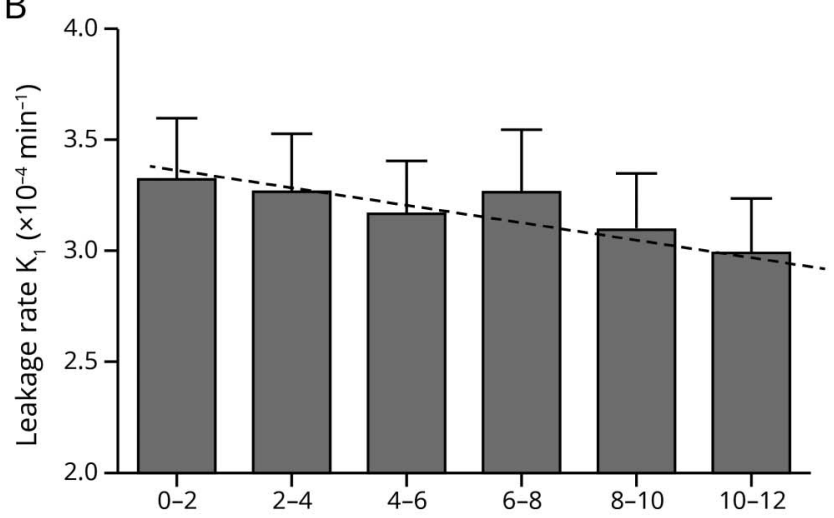

C

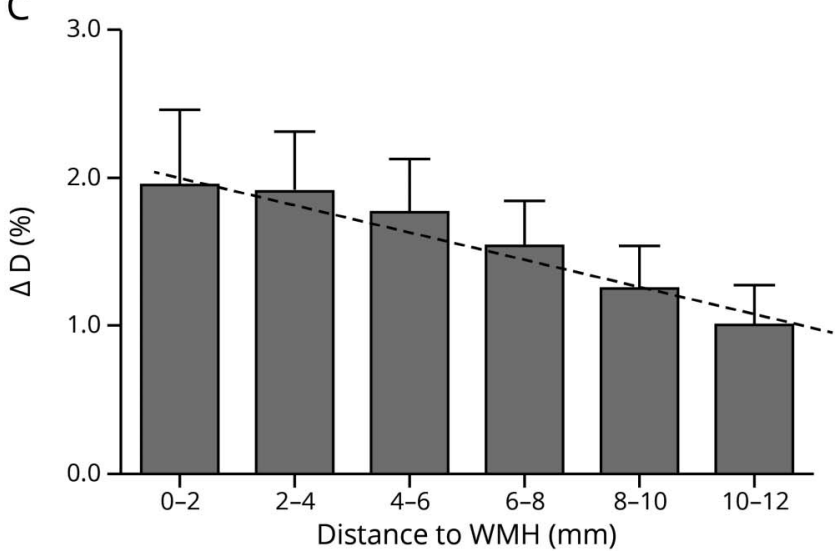

Spatial variation in leakage volume $\mathrm{v}_{\mathrm{L}}(\mathrm{A})$, leakage rate $K_{\mathrm{i}}(\mathrm{B})$, and longitudinal change in parenchymal diffusivity $\triangle D(C)$ in the perilesional zones around the white matter hyperintensities $(\mathrm{WMH})$. Corresponding regression lines of the values per perilesional zone are plotted (dashed).

leakage near the WMH showed that both BBB leakage volume and leakage rate increase in proximity to the lesion: leakage volume vL increased $0.7[0.4,1.0] \%(p<0.01)$ and leakage rate $K_{\mathrm{i}} 0.30(0.09-0.51) \times 10^{-5} \mathrm{~min}^{-1}(p=0.018)$ per $2 \mathrm{~mm}$ closer to the WMH. Also, the longitudinal change in diffusivity $\Delta D$ was higher adjacent to the $\mathrm{WMH}$ compared with zones that are more distant: $\Delta D$ of $2.0 \%$ compared to $1.0 \%$ in 2 and $12 \mathrm{~mm}$ distance from $\mathrm{WMH}$ borders, respectively. $\Delta D$ increased $0.10[0.07,0.13] \%(p<0.01)$ per $2 \mathrm{~mm}$ closer to the WMH.

Two analyses were performed to investigate the relation between the leakage measures and the longitudinal change $\Delta D$ in the perilesional zone. First, for every individual patient, we investigated the longitudinal change in diffusivity $\Delta D$ over the zones surrounding the $\mathrm{WMH}$ in correlation to baseline leakage volume $v_{\mathrm{L}}$ and leakage rate $K_{\mathrm{i}}$. Both baseline leakage volume $v_{\mathrm{L}}$ and leakage rate $K_{\mathrm{i}}$ showed a significant positive correlation with the longitudinal change in diffusivity $\Delta D$ over the zones around the WMH $\left(v_{\mathrm{L}}: r=0.29\right.$ [0.06-0.52], $p=$ $\left.0.013 ; K_{\mathrm{i}}: r=0.24[0.02-0.47], p=0.034\right)$. We further tested whether the individual correlations between baseline leakage and change in diffusivity are associated with different risk factors (including age, sex, hypertension, type II diabetes, Fazekas score, and relative WMH volume). No associations were found between the risk factors and the individual correlations (data not shown, available upon request).

In the second analysis, the relation between the mean leakage volume $v_{L}$ and mean leakage rate $K_{i}$ and the mean longitudinal change in diffusivity $\Delta D$ over all patients in the $\mathrm{WMH}$ perilesional zones is presented in figure 3 . Both leakage volume and leakage rate are significantly associated with the longitudinal change in diffusivity $\Delta D$ around the WMH: per $10 \%$ higher baseline leakage volume $v_{\mathrm{L}}$, the longitudinal change in diffusivity $\Delta D$ increases $1.4 \%(\beta=$ $0.960, p=0.002$ ) and per $1 \times 10^{-3} \mathrm{~min}^{-1}$ higher leakage rate $K_{\mathrm{i}}$, the longitudinal change in diffusivity $\Delta D$ increases $2.7 \%$ $(\beta=0.895, p=0.016)$.

\section{Discussion}

In this longitudinal study in patients with cSVD, we examined $\mathrm{BBB}$ leakage at baseline in relation to change in parenchymal diffusivity over 2 years in the perilesional zones of $\mathrm{WMH}$. We found that the longitudinal increase in parenchymal diffusivity over 2 years, representing decrease in microstructural tissue integrity, was higher adjacent to the $\mathrm{WMH}$ in comparison to more remotely located NAWM. This stronger longitudinal increase in parenchymal diffusivity in the proximity of the $\mathrm{WMH}$ was positively associated with locally higher $\mathrm{BBB}$ leakage volume and rate at baseline.

Loss of tissue integrity in the NAWM directly surrounding the $\mathrm{WMH}$ is of increasing interest as it has been shown to precede conversion into WMH over time. ${ }^{30,31}$ Furthermore, it has been demonstrated that loss of tissue integrity of the NAWM was associated with cognitive performance in patients with cSVD. ${ }^{32}$ Loss of tissue integrity is represented by increased brain tissue water measured with IVIM as an increased parenchymal diffusivity. ${ }^{33}$ In agreement with cross-sectional studies, we showed increased diffusivity closer towards $\mathrm{WMH}$, and in addition we found the change in diffusivity over time increasing in proximity to $\mathrm{WMH} \cdot{ }^{10,34}$ The longitudinal change in diffusivity in the 
Figure 3 Scatterplots Between Longitudinal Change in Parenchymal Diffusivity, Leakage Volume, and Leakage Rate
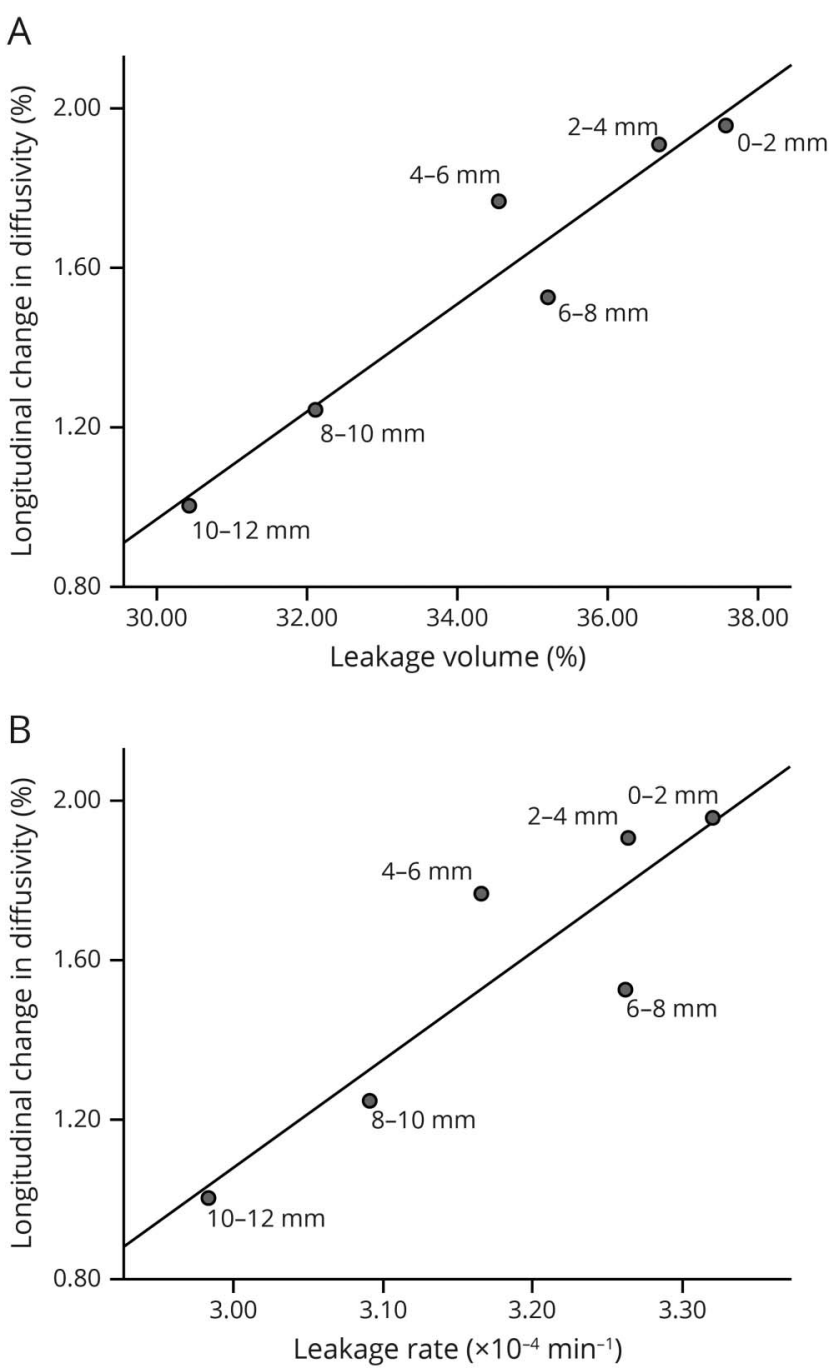

Scatterplot between leakage volume $\mathrm{v}_{\mathrm{L}}(\%)$ and longitudinal change in parenchymal diffusivity $\Delta D(\%)(\mathrm{A})$ and between leakage rate $K_{\mathrm{i}}\left(\times 10^{-4} \mathrm{~min}^{-1}\right)$ and longitudinal change in parenchymal diffusivity $\Delta D(\%)(B)$ in the perilesional zones around the white matter hyperintensities with corresponding regression line.

closest perilesional contours was even higher than in the WMH itself, reflecting that the perilesional zones are at risk. Probably tissue within $\mathrm{WMH}$ is damaged already to such an extent that further tissue loss is attenuating.

Increase in permeability of the BBB is assumed to play an initiating and important role in the pathogenesis of cSVD. Leakage of the BBB is associated with total WMH volume and predicts cognitive decline. ${ }^{9,10}$ Similar to our study, BBB permeability in the white matter was previously found to be increased in the proximity to $\mathrm{WMH} .^{10,14,35}$

In the present study, which has a longitudinal setup, we show that $\mathrm{BBB}$ leakage measured at baseline in the perilesional zones surrounding the WMH is spatially related to a higher increase in tissue diffusivity over 2 years. This observed link between $\mathrm{BBB}$ leakage at baseline and loss of microstructural integrity over time in the zones around the $\mathrm{WMH}$ is a novel finding that supports the idea that increased permeability of the BBB leads to microstructural damage before (extension of) morphologic abnormalities become visible on brain MRI as $\mathrm{WMH} .{ }^{36,37}$ The neurovascular unit (NVU) is an important component in the brain regulating the functioning of the $\mathrm{BBB}$ as a selective barrier and thereby maintaining a healthy tissue environment. Impairment of the $\mathrm{BBB}$ can influence other elements of the NVU including changes in extracellular matrix components, pericytes, and inflammatory cells, which affect the local brain tissue. ${ }^{38-40}$ Our results are in line with the hypothesis that there is an impaired functioning of the NVU in $\mathrm{CSVD}$ as also shown in a previous study, where BBB impairment was related to hypoperfusion. ${ }^{14}$

In contrast to the perilesional zones around the $\mathrm{WMH}$, we did not observe an association between longitudinal change in diffusivity and $\mathrm{BBB}$ leakage in the larger tissue regions (i.e., total NAWM, CGM, or WMH). The CGM and NAWM tissue regions are probably too large and heterogeneous and disguise local pathophysiologic effects such as in the perilesional zone. Furthermore, as WMH already comprises tissue with abnormal tissue integrity and decreased perfusion, this could explain why we do not find an association between $\mathrm{BBB}$ leakage and change in tissue integrity in the $\mathrm{WMH}{ }^{41}$

Short-term progression of cSVD is difficult to monitor as visible MRI markers such as WMH progress slowly over time. Parenchymal diffusivity has been shown to be the most promising measure to detect longitudinal changes. ${ }^{42}$ We demonstrated in the present study the possibility to detect microstructural changes over 2 years in the vulnerable tissue surrounding the visible WMH with IVIM imaging. Parenchymal diffusivity in the proximity of WMH can be a promising quantitative biomarker for monitoring on prevention and treatment efficacy in trials in $\mathrm{cSVD}$.

A major strength of the current study is the longitudinal design. It enabled us to investigate a temporal relation between BBB leakage and longitudinal change in microstructural integrity. Identical IVIM sequences on the same MRI scanner were used during baseline and follow-up, which makes direct comparison of both scans straightforward. Furthermore, IVIM provides a less contaminated measure for parenchymal diffusivity compared to standard diffusion MRI. The correction for the vascular contribution with IVIM imaging is important to avoid direct influence from microvascular perfusion, which is also altered in the perilesional zones. ${ }^{14}$ $\mathrm{BBB}$ permeability was assessed for both leakage volume and leakage rate. Leakage volume is a relative new measure to examine BBB permeability. We previously found that leakage 
volume is higher in patients with cSVD compared to age- and sex-matched controls, indicating that leakage volume is a sensitive measure for BBB leakage. ${ }^{7}$

A limitation of this study is that the short follow-up period may have underestimated the associations found in this study. However, the relatively short period underlines the susceptibility of the IVIM technique and emphasizes the early role of the BBB breakdown (and NVU impairment) for the limited time for other pathophysiologic processes to interfere. Future studies should examine longitudinal change in microstructural integrity in a larger patient cohort over a longer time period, and also in patients with less WMH load. Another limitation of this study is that we only assessed BBB permeability at baseline. Therefore we have no indication of any change in BBB permeability over time and the association with tissue degeneration, which would be of interest for future studies. Furthermore, it is conceivable that the association between $\mathrm{BBB}$ leakage and longitudinal increasing diffusivity is due to another common underlying factor or mechanism.

In patients with cSVD, we showed that the increase in parenchymal diffusivity over 2 years was strongest in proximity of the WMH (and even higher than within WMH itself). Our results also demonstrate that $\mathrm{BBB}$ leakage at baseline is related to this change in perilesional white matter diffusivity, and therefore tissue integrity. This observation supports the hypothesis that BBB impairment plays an early and pivotal role in subsequent microstructural white matter degeneration and the pathophysiology of cSVD. In the future, measures of BBB leakage may be used to identify patients at risk for development and progression of tissue degeneration. The longitudinal change in parenchymal diffusivity measured with IVIM is a promising quantitative biomarker for monitoring in cSVD trials.

\section{Acknowledgment}

The authors thank Dr. Erik Hoff and Tobien Schreuder for help with recruitment.

\section{Study Funding}

This project has received funding from the European Union's Horizon 2020 research and innovation programme under grant agreement 666881, SVDs@target; NWO (Netherlands Organisation for Scientific Research), grant 017.009.048; Hersenstichting, grant 2013(1)-195; and Stichting de Weijerhorst Foundation.

\section{Disclosure}

The authors report no disclosures. Go to Neurology.org/N for full disclosures.

\section{Publication History}

Received by Neurology October 11, 2020. Accepted in final form January 29, 2021.

\section{Appendix Authors}

\begin{tabular}{|c|c|c|}
\hline Name & Location & Contribution \\
\hline $\begin{array}{l}\text { Danielle } \\
\text { Kerkhofs, MD }\end{array}$ & $\begin{array}{l}\text { Maastricht } \\
\text { University, the } \\
\text { Netherlands }\end{array}$ & $\begin{array}{l}\text { Drafting/revising the manuscript, } \\
\text { analysis or interpretation of the } \\
\text { data, statistical analysis }\end{array}$ \\
\hline $\begin{array}{l}\text { Sau May Wong, } \\
\text { PhD }\end{array}$ & $\begin{array}{l}\text { Maastricht } \\
\text { University, the } \\
\text { Netherlands }\end{array}$ & $\begin{array}{l}\text { Drafting/revising the manuscript, } \\
\text { data acquisition, analysis or } \\
\text { interpretation of the data }\end{array}$ \\
\hline $\begin{array}{l}\text { Eleana Zhang, } \\
\text { PhD, MD }\end{array}$ & $\begin{array}{l}\text { Maastricht } \\
\text { University, the } \\
\text { Netherlands }\end{array}$ & $\begin{array}{l}\text { Data acquisition, review of } \\
\text { manuscript }\end{array}$ \\
\hline $\begin{array}{l}\text { Julie Staals, MD, } \\
\text { PhD }\end{array}$ & $\begin{array}{l}\text { Maastricht } \\
\text { University, the } \\
\text { Netherlands }\end{array}$ & $\begin{array}{l}\text { Drafting/revising the manuscript, } \\
\text { study concept or design, analysis } \\
\text { or interpretation of the data }\end{array}$ \\
\hline $\begin{array}{l}\text { Jacobus F.A. } \\
\text { Jansen, PhD }\end{array}$ & $\begin{array}{l}\text { Maastricht } \\
\text { University, the } \\
\text { Netherlands }\end{array}$ & $\begin{array}{l}\text { Drafting/revising the manuscript, } \\
\text { data acquisition, study concept } \\
\text { or design, analysis or } \\
\text { interpretation of the data }\end{array}$ \\
\hline $\begin{array}{l}\text { Robert J. van } \\
\text { Oostenbrugge, } \\
\text { PhD, MD }\end{array}$ & $\begin{array}{l}\text { Maastricht } \\
\text { University, the } \\
\text { Netherlands }\end{array}$ & $\begin{array}{l}\text { Drafting/revising the manuscript, } \\
\text { study concept or design, analysis } \\
\text { or interpretation of the data }\end{array}$ \\
\hline $\begin{array}{l}\text { Walter H. } \\
\text { Backes, PhD }\end{array}$ & $\begin{array}{l}\text { Maastricht } \\
\text { University, the } \\
\text { Netherlands }\end{array}$ & $\begin{array}{l}\text { Drafting/revising the manuscript, } \\
\text { study concept or design, analysis } \\
\text { or interpretation of the data }\end{array}$ \\
\hline
\end{tabular}

\section{References}

1. Pantoni L. Cerebral small vessel disease: from pathogenesis and clinical characteristics to therapeutic challenges. Lancet Neurol. 2010;9:689-701.

2. Wardlaw JM, Smith EE, Biessels GJ, et al. Standards For Reporting Vascular Changes on Neuroimaging (STRIVE v1): Neuroimaging standards for research into small vessel disease and its contribution to ageing and neurodegeneration. Lancet Neurol. 2013;12:822-838.

3. Hainsworth AH, Minett T, Andoh J, et al. Neuropathology of white matter lesions, blood-brain barrier dysfunction, and dementia. Stroke. 2017;48:2799-2804.

4. de Laat KF, Tuladhar AM, van Norden AG, Norris DG, Zwiers MP, de Leeuw F-E. Loss of white matter integrity is associated with gait disorders in cerebral small vessel disease. Brain. 2011;134:73-83.

5. Van der Flier WM, van Straaten EC, Barkhof F, et al. Small vessel disease and general cognitive function in nondisabled elderly: the LADIS study. Stroke. 2005;36:2116-2120.

6. Wardlaw JM, Doubal F, Armitage P, et al. Lacunar stroke is associated with diffuse blood-brain barrier dysfunction. Ann Neurol. 2009;65:194-202.

7. Zhang CE, Wong SM, van de Haar HJ, et al. Blood-brain barrier leakage is more widespread in patients with cerebral small vessel disease. Neurology. 2017;88:426-432.

8. Li Y, Li M, Zhang X, et al. Higher blood-brain barrier permeability is associated with higher white matter hyperintensities burden. J Neurol. 2017;264:1474-1481.

9. Zhang CE, Wong SM, Uiterwijk R, et al. Blood-brain barrier leakage in relation to white matter hyperintensity volume and cognition in small vessel disease and normal aging. Brain Imaging Behav. 2019;13:389-395.

10. Wardlaw JM, Makin SJ, Hernández MCV, et al. Blood-brain barrier failure as a core mechanism in cerebral small vessel disease and dementia: evidence from a cohort study. Alzheimers Demen. 2017;13:634-643.

11. Le Bihan D, Breton E, Lallemand D, Aubin M, Vignaud J, Laval-Jeantet M. Separation of diffusion and perfusion in intravoxel incoherent motion MR imaging. Radiology. 1988; 168:497-505.

12. Wong SM, Zhang CE, van Bussel FC, et al. Simultaneous investigation of microvasculature and parenchyma in cerebral small vessel disease using intravoxel incoherent motion imaging. Neuroimage Clin. 2017;14:216-221.

13. Sagnier S, Catheline G, Dilharreguy B, et al. Normal-appearing white matter integrity is a predictor of outcome after ischemic stroke. Stroke. 2020;51:449-456.

14. Wong SM, Jansen JF, Zhang CE, et al. Blood-brain barrier impairment and hypoperfusion are linked in cerebral small vessel disease. Neurology. 2019;92: e1669-e1677.

15. Bamford J, Sandercock P, Jones L, Warlow C. The natural history of lacunar infarction: the Oxfordshire Community Stroke Project. Stroke. 1987;18:545-551.

16. Wardlaw JM, Smith EE, Biessels GJ, et al. Neuroimaging standards for research into small vessel disease and its contribution to ageing and neurodegeneration. Lancet Neurol. 2013;12:822-838.

17. Gorelick PB, Scuteri A, Black SE, et al. Vascular contributions to cognitive impairment and dementia: a statement for healthcare professionals from the American Heart Association/American Stroke Association. Stroke. 2011;42:2672-2713. 
18. Fazekas F, Chawluk JB, Alavi A, Hurtig HI, Zimmerman RA. MR signal abnormalities at $1.5 \mathrm{~T}$ in Alzheimer's dementia and normal aging. AJR Am J Roentgenol. 1987;149: 351-356.

19. Van De Haar HJ, Burgmans S, Jansen JF, et al. Blood-brain barrier leakage in patients with early Alzheimer disease. Radiology. 2016;281:527-535.

20. Duering M, Csanadi E, Gesierich B, et al. Incident lacunes preferentially localize to the edge of white matter hyperintensities: insights into the pathophysiology of cerebral small vessel disease. Brain. 2013;136:2717-2726.

21. Larsson HB, Courivaud F, Rostrup E, Hansen AE. Measurement of brain perfusion, blood volume, and blood-brain barrier permeability, using dynamic contrastenhanced T1-weighted MRI at 3 tesla. Magn Reson Med. 2009;62:1270-1281.

22. van Bussel FC, Backes WH, Hofman PA, et al. On the interplay of microvasculature, parenchyma, and memory in type 2 diabetes. Diabetes Care. 2015;38:876-882.

23. Hales PW, Clark CA. Combined arterial spin labeling and diffusion-weighted imaging for noninvasive estimation of capillary volume fraction and permeability-surface product in the human brain. J Cereb Blood Flow Metab. 2013;33:67-75.

24. Patlak CS, Blasberg RG. Graphical evaluation of blood-to-brain transfer constants from multiple-time uptake data. Generalizations. J Cereb Blood Flow Metab. 1985;5: 584-590.

25. Leemans A, Jeurissen B, Sijbers J, Jones D. ExploreDTI: a graphical toolbox for processing, analyzing, and visualizing diffusion MR data. Proc Intl Soc Mag Reson Med. 2009;17:3537.

26. Federau C, O’Brien K, Meuli R, Hagmann P, Maeder P. Measuring brain perfusion with intravoxel incoherent motion (IVIM): initial clinical experience. J Magn Reson Imaging. 2014;39:624-632.

27. Fischl B. FreeSurfer. Neuroimage. 2012;62:774-781.

28. De Boer R, Vrooman HA, Van Der Lijn F, et al. White matter lesion extension to automatic brain tissue segmentation on MRI. Neuroimage. 2009;45:1151-1161.

29. Jenkinson M, Bannister P, Brady M, Smith S. Improved optimization for the robust and accurate linear registration and motion correction of brain images. Neuroimage. $2002 ; 17: 825-841$.
30. Van Leijsen EM, Bergkamp MI, Van Uden IW, et al. Progression of white matter hyperintensities preceded by heterogeneous decline of microstructural integrity. Stroke. 2018;49:1386-1393.

31. De Groot M, Verhaaren BF, De Boer R, et al. Changes in normal-appearing white matter precede development of white matter lesions. Stroke. 2013;44:1037-1042.

32. van Norden AG, de Laat KF, van Dijk EJ, et al. Diffusion tensor imaging and cognition in cerebral small vessel disease: the RUN DMC study. Biochim Biophys Acta. 2012; 1822:401-407.

33. Alexander AL, Lee JE, Lazar M, Field AS. Diffusion tensor imaging of the brain. Neurotherapeutics. 2007;4:316-329.

34. Maniega SM, Hernández MCV, Clayden JD, et al. White matter hyperintensities and normal-appearing white matter integrity in the aging brain. Neurobiol Aging. 2015;36: 909-918.

35. Huisa BN, Caprihan A, Thompson J, Prestopnik J, Qualls CR, Rosenberg GA. Longterm blood-brain barrier permeability changes in Binswanger disease. Stroke. 2015; 46:2413-2418.

36. Rosenberg GA, Wallin A, Wardlaw JM, et al. Consensus statement for diagnosis of subcortical small vessel disease. J Cereb Blood Flow Metab. 2016;36:6-25.

37. Young VG, Halliday GM, Kril JJ. Neuropathologic correlates of white matter hyperintensities. Neurology. 2008;71:804-811.

38. Iadecola C. The neurovascular unit coming of age: a journey through neurovascular coupling in health and disease. Neuron. 2017;96:17-42.

39. Del Zoppo GJ. The neurovascular unit, matrix proteases, and innate inflammation. Ann NY Acad Sci. 2010;1207:46-49.

40. Sweeney MD, Zhao Z, Montagne A, Nelson AR, Zlokovic BV. Blood-brain barrier: from physiology to disease and back. Physiol Rev. 2019;99:21-78.

41. O'Sullivan M, Lythgoe D, Pereira A, et al. Patterns of cerebral blood flow reduction in patients with ischemic leukoaraiosis. Neurology. 2002;59:321-326.

42. Zeestraten EA, Benjamin P, Lambert C, et al. Application of diffusion tensor imaging parameters to detect change in longitudinal studies in cerebral small vessel disease. PLoS One. 2016;11:e0147836. 


\section{Neurology}

\section{Baseline Blood-Brain Barrier Leakage and Longitudinal Microstructural Tissue Damage in the Periphery of White Matter Hyperintensities}

Danielle Kerkhofs, Sau May Wong, Eleana Zhang, et al.

Neurology 2021;96;e2192-e2200 Published Online before print March 24, 2021

DOI 10.1212/WNL.0000000000011783

This information is current as of March 24, 2021

\section{Updated Information \&} Services

References

Subspecialty Collections

Permissions \& Licensing

Reprints including high resolution figures, can be found at: http://n.neurology.org/content/96/17/e2192.full

This article cites 42 articles, 12 of which you can access for free at: http://n.neurology.org/content/96/17/e2192.full\#ref-list-1

This article, along with others on similar topics, appears in the following collection(s):

MRI

http://n.neurology.org/cgi/collection/mri

Other cerebrovascular disease/ Stroke

http://n.neurology.org/cgi/collection/other_cerebrovascular_disease_s troke

Information about reproducing this article in parts (figures,tables) or in its entirety can be found online at:

http://www.neurology.org/about/about_the_journal\#permissions

Information about ordering reprints can be found online:

http://n.neurology.org/subscribers/advertise

Neurology ${ }^{\circledR}$ is the official journal of the American Academy of Neurology. Published continuously since 1951, it is now a weekly with 48 issues per year. Copyright Copyright (C) 2021 The Author(s). Published by Wolters Kluwer Health, Inc. on behalf of the American Academy of Neurology.. All rights reserved. Print ISSN: 0028-3878. Online ISSN: 1526-632X.

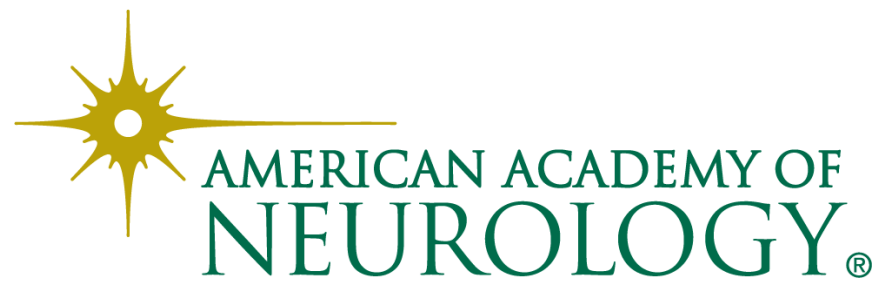

